\title{
ACOEM Guideline Analysis
}

\section{TO THE EDITOR:}

The recent series of 3 articles published in Pain Physician regarding the ACOEM guidelines represented a significant new approach to evidence analysis and guideline synthesis by the addition of guideline criticism (1-3). The manner in which the articles were written attempt to objectively and strictly apply the methods of analysis and synthesis as proposed by prominent agencies and medical societies, and to also apply strictly ACOEM's own method with the addition of overlooked literature. The results of such analysis are shocking.

\section{New Approach}

It is unusual for medicine to see one medical society publish a sweeping reanalysis of another society's guidelines regarding an entire discipline, such as Interventional Pain Management, or to criticize the manner so thoroughly, then reapply analytic criteria to reach different conclusions. What is the purpose of this?

The ACOEM guidelines regarding spine interventions and surgery are exceedingly negative, thereby threatening the existence of the specialty of Interventional Pain Management. Logically, a reaction was drawn. Rather than a simple emotional criticism pointing out the flaws of the ACOEM publication, the authors present the reader details of proper evidence analysis and guideline analysis that are generally accepted. The authors then guide the reader in the correct application of the method.

\section{Objectivity and Standards}

The various standards of evidence analysis such as the Agency for Healthcare Research and Quality (AHRQ) (4) and Cochrane (5), the grading of recommendations modified from Guyat et al (6) and those of ASIPP (7), and the formulation of guidelines all have some logical appeal to physicians and payers. The validity of such standards may be questioned. One would have to subject such analysis, recommendations, and guidelines themselves to 2 cohort prospective studies with randomization. We might discover that our community's perception of wellness is better following the ASIPP guidelines (7) more so than a cohort following the ACOEM guidelines $(8,9)$ that would not allow coverage of interventional techniques; or the opposite may become apparent.

The method of ACOEM is not validated either, and excludes a couple of clinical variables that may be important. Manchikanti et al (3) stated, "While there is no universally accepted approach to developing and presenting guidelines...," impling that we cannot place $100 \%$ of faith in any of the methods. However, one should logically conclude that more rigor and inclusion of more evidence would be additive to the reliability of conclusions. Patients deserve best efforts.

AHCPR funding has been stopped by congress because the application of guidelines was found to be controversial and too restricting on medical practice; the development of the 19 guidelines they issued was at an expense of $\$ 750$ million taxpayer dollars (10). The US may be better able to afford the continuation of controversial practices than to try to develop guidelines that everyone can agree are valid.

The refusal to consider well designed observational studies is both without validity and does disservice to the public by ignoring important developments and valuable evidence. The value of RCTs in the study of comparative efficacy of 2 similar drugs has not been demonstrated to be a valid or necessary method of studying procedures. The cost of RCT's and the ethical issues involved when enrolling patients in such studies for procedures dictates more extensive literature evaluation and the experience of experts in the specialty.

\section{Results}

The first article (1) detailed the proper methods and rating systems accepted in medicine. The article pointed out the conflicts of interest that could introduce bias into the ACOEM method and conclusions.

The second article (2) did assess the methods applied in the ACOEM guidelines applying the AGREE instrument. The scores received by the ACOEM guidelines for the low back and chronic pain chapters, including interventional pain guidelines, were dismally poor, a failure by any academic standard: $<10 \%$ in 3 of 6 domains, $<20 \%$ in $1 / 6,>30 \%$ in $1 / 6$, and $>70 \%$ in only $1 / 6$; the overall score was $<30 \%$. The AGREE instrument dictates that one conclude, "not recommended or suitable for use in practice." The guidelines also disastrously fail using AMA and IOM criteria.The analysis used measurement tools as mentioned above. 
ACOEM response by Hegmann et al (10) to the first 2 articles was, in contrast, an emotional response lacking evidence, method, and objectivity. It was a sophomoric attempt to dismiss a well crafted critique that one would prefer they take very constructively. It failed to address a basic criticism such as inclusion of the Caragee article on discography that compared isthmic spondylolisthesis surgical outcome to fusion outcomes for painful degenerative discs. This article did not meet their own inclusion criteria as there was no rational randomization and comparabitlity of the 2 cohorts, yet was part of the basis of their recommendation.

In the third article (3), the negligent exclusion of articles that score highly by proper adherence to methodology was revealed. Very different conclusions are reached when rigor is applied, even utilizing their own system, favoring diagnostic use of provocation discography, facet diagnostics, and therapeutics, lumbar transforaminal epidural steroid injection, sacroiliac injection, adhesiolysis, and spinal cord stimulation which are strong; for facet neurolysis moderate to strong; for caudal epidural steroid injection moderate evidence with positive results short-term, limited longterm, but overall Level 1 by AHRQ standards; while ACOEM methodology finds interlaminar epidural steroid injection insufficiently documented, Guyatt style analysis is $1 \mathrm{~A}$ or $1 \mathrm{~B}$ for cervical, $2 \mathrm{~A}$ or $\mathrm{C}$ for lumbar.

These results are shockingly different from those presented by ACOEM.

\section{Ethical Questions}

- $\quad$ Should guidelines in a specialty area be issued by that specialty society only? Are members of other societies expert enough to thoroughly understand the nature and intricacies of a different discipline?

- Will insurance companies and agencies reappraise the validity of ACOEM guidelines and stop using them in favor of guidelines that strictly apply the current standards of evidence analysis and guideline synthesis. And score highly on the AGREE assessment?

- How should society at large react if payers fail to adhere to the principles?
- When an agency or company refuses patients access to justifiable services, are they negligent or guilty of a form of malpractice?

- $\quad$ Are they endangering the well-being and productivity of our community in the interest of their balance sheets?

- Will denial of coverage for our procedures widen the gap in care between the rich who can afford to pay for elective procedures and those who are dependent on coverage for care?

- Will the denial of coverage for pain interventions result in more people being shifted into disability and increase our social security burden?

- Is there any financial relationship between the ACOEM investigators and payers? If so, is that okay or should that be disclosed in parcel with the ACOEM guidelines?

\section{In Closing}

One assumes that guidelines that will be used to influence payer coverage would adhere to the highest standard and methodology. When it does not, as it appears here to have failed, then one is truly disappointed and left feeling betrayed. Most importantly, payers have been citing these apparently unreliable guidelines as a basis to deny coverage for interventional techniques. Garbage in, garbage out is too simple an excuse when patient well being is at stake. Government agencies and the public should join multiple medical societies in questioning the appropriateness and responsibility of payers who follow guidelines that are scoring so poorly when the AGREE instrument is applied. Thus far multiple medical societies and members of Congress have voiced their protest $(11,12)$. The public and Legislators should be concerned about the expansion of Social Security burdens when citizens lack access to pain control due to denial of coverage in worker's compensation, state agency, or private sectors.

Joseph Jasper, MD

Medical Director

Advanced Pain Medicine Physicians

Tacoma, WA

E-mail: apmedicine@qwest.net

\section{References}

1. Manchikanti L, Singh V, Derby R, Helm $S$, Trescot AM, Staats PS, Prager JP, Hirsch JA. Review of occupational medicine practice guidelines for interven- tional pain management and potential implications. Pain Physician 2008; 11:271-289.

2. Manchikanti L, Singh V, Helm S, Trescot
AM, Hirsch JA. A critical appraisal of 2007 American College of Occupational and Environmental Medicine (ACO$E M)$ practice guidelines for interven- 
tional pain management: An independent review utilizing AGREE, AMA, IOM, and other criteria. Pain Physician 2008; 11:291-310.

3. Manchikanti L, Singh V, Derby R, Schultz DM, Benyamin RM, Prager JP, Hirsch JA. Reassessment of evidence synthesis of occupational medicine practice guidelines for interventional pain management. Pain Physician 2008; 11:393-482.

4. West S, King V, Carey TS, Lohr KN, McKoy N, Sutton SF, Lux L. Systems to Rate the Strength of Scientific Evidence, Evidence Report, Technology Assessment No. 47. AHRQ Publication No. 02E016. Rockville, MD: Agency for Healthcare Research and Quality, 2002. www. thecre.com/pdf/ahrq-system-strength. pdf

5. Koes BW, Scholten RJ, Mens JMA, Bouter LM. Epidural steroid injections for low back pain and sciatica. An updated systematic review of randomized clinical trials. Pain Digest 1999; 9:241-247.

6. Guyatt $\mathrm{G}$, Gutterman D, Baumann MH,
Addrizzo-Harris D, Hylek EM, Phillips B, Raskob G, Lewis SZ, Schünemann H. Grading strength of recommendations and quality of evidence in clinical guidelines. Report from an American College of Chest Physicians Task Force. Chest 2006; 129:174-181.

7. Boswell MV, Shah RV, Everett CR, Sehgal N, Mckenzie-Brown AM, Abdi S, Bowman RC, Deer TR, Datta S, Colson JD, Spillane WF, Smith HS, LucasLevin LF, Burton AW, Chopra P, Staats PS, Wasserman RA, Manchikanti L. Interventional techniques in the management of chronic spinal pain: Evidencebased practice guidelines. Pain Physician 2005; 8:1-47

8. American College of Occupational and Environmental Medicine (ACOEM) Low Back Disorders. In Occupational Medicine Practice Guidelines: Evaluation and Management of Common Health Problems and Functional Recovery of Work ers, Second Edition. OEM Press, Beverly Farms, 2007.

9. American College of Occupational and Environmental Medicine (ACOEM) Chronic Pain. In Occupational Medicine Practice Guidelines: Evaluation and Management of Common Health Problems and Functional Recovery of Workers, Second Edition. OEM Press, Beverly Farms; awaiting publication.

10. Hegmann KT, Talmaga JB, Genovese E. In Reference to Manchikanti et al's Criticism of ACOEM Guidelines. Pain Physician 2008; 11:567-568.

11. Letter to Robert K. McLellan, MD, President of the American College of Occupational \& Environmental Medicine (ACOEM) from the American Academy of Pain Medicine, American Society of Interventional Pain Physicians, International Spine Intervention Society, and North American Neuromodulation Society. January 22, 2008.

12. Letter to Robert K. McLellan, MD, President of the American College of Occupational \& Environmental Medicine (ACOEM) from the Honorable Bart Stupak and Ed Whitfield, U.S. House of Representatives, January 25, 2008. 